\title{
Hydrophobic surface functionalization of lignocellulosic jute fabrics by enzymatic grafting of octadecylamine
}

\author{
Aixue Donga ${ }^{\mathrm{a}}$, Xuerong Fan ${ }^{\mathrm{a}, \mathrm{b}}$, Qiang Wang ${ }^{\mathrm{a}, \mathrm{b}, *}$, Yuanyuan Yua ${ }^{\mathrm{a}}$, Artur Cavaco-Paulo ${ }^{\mathrm{b}, \mathrm{c}}$ \\ ${ }^{a}$ Key Laboratory of Science and Technology of Eco-Textile, Ministry of Education, Jiangnan University, Wuxi 214122, Jiangsu, China \\ b International Joint Research Laboratory for Textile and Fiber Bioprocesses, Jiangnan University, Wuxi 214122, Jiangsu, China

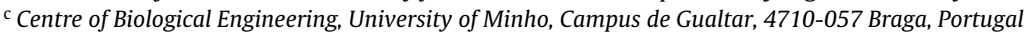

\section{A R T I C L E I N F O}

\section{Article history:}

Received 2 February 2015

Received in revised form 7 May 2015

Accepted 11 May 2015

Available online 15 May 2015

\section{Keywords:}

Jute

Laccase

Grafting

\begin{abstract}
A B S T R A C T
Enzymatic grafting of synthetic molecules onto lignins provides a mild and eco-friendly alternative for the functionalization of lignocellulosic materials. In this study, laccase-mediated grafting of octadecylamine $(\mathrm{OA})$ onto lignin-rich jute fabrics was investigated for enhancing the surface hydrophobicity. First, the lignins in jute fabrics were isolated and analyzed in the macromolecular level by MALDI-TOF MS, ${ }^{1} \mathrm{H}$ NMR, ${ }^{13} \mathrm{C}$ NMR, and HSQC-NMR. Then, the surface of jute fabrics was characterized by FT-IR, XPS, and SEM. Subsequently, the nitrogen content of jute fabrics was determined by the micro-Kjeldahl method, and the grafting percentage (Gp) and grafting efficiency (GE) of the enzymatic reaction were calculated. Finally, the surface hydrophobicity of the jute fabrics was estimated by contact angle and wetting time measurements. The results indicate that the OA monomers were successfully grafted onto the lignin moieties on the jute fiber surface by laccase with Gp and GE values of $0.712 \%$ and $10.571 \%$, respectively. Moreover, the modified jute fabrics via OA-grafting showed an increased wetting time of $18.5 \mathrm{~min}$ and a contact angle of $116.72^{\circ}$, indicating that the surface hydrophobicity of the jute fabrics increased after the enzymatic grafting modification with hydrophobic OA molecules.
\end{abstract}

(C) 2015 Elsevier B.V. All rights reserved.

\section{Introduction}

With increasing demand of sustainable development around the world, natural jute fiber has drawn a wide public attention in various applications owing to its merits of low cost, abundant supply, biodegradability, and renewability [1]. As a rich lignocellulosic bioresource, jute fiber is considered as one of the most valuable natural fiber and occupies the second place in the world production after cotton [2]. In the past, jute was mainly used to produce low-value bags, carpets, upholsteries, and handicrafts. Nowadays, the application of jute has expanded from home textiles to industrial products, including the manufacturing of clothes, papers, fiberboards, geotextiles, fiber-reinforced composites, and cellulose nanofibrils [2-5]. Jute materials exhibit strong hydrophilicity and high moisture absorption because of numerous hydroxyl groups in their cellulosic components [6]. However, jute materials with hydrophobic characteristics are often needed for some industrial

\footnotetext{
* Corresponding author at: Jiangnan University, Key Laboratory of Science and Technology of Eco-Textile, 1800 Lihu Ave., Wuxi 214122, Jiangsu, China. Tel.: +86510 85912240.

E-mail address: qiang_wang@163.com (Q. Wang).
}

and engineering applications, e.g., in the fiber reinforcement of resin matrix composites $[7,8]$ and technical fabrics for outdoors. To develop jute products with a higher performance or added value, the surface of jute fiber should be modified accordingly, from its original hygroscopic characteristics to hydrophobic characteristics.

Traditionally, graft polymerization $[9,10]$ and coupling $[11,12]$ have been used as two common approaches for the surface hydrophobization of natural lignocellulosic fibers. However, these chemical methods have some inherent shortcomings. The graft copolymerization initiated by chemical initiators or high-energy rays has been shown to form homopolymers. Moreover, the grafting process may have several other disadvantages such as difficulty to industrialize, contaminated with residual toxic initiators, and damage to fibers. The lignin present in the lignocellulosic fibers also plays a negative role in the polymerization, causing more consumption of oxidizing initiators than other natural fibers such as cotton. Although the treatment of fiber surfaces with organic silicon coupling agents has gained much success in improving the hydrophobicity, it has disadvantages of multistep procedures and the waste disposal of emulsifiers present on the surface after the treatment. Moreover, the current increasing concern on environmental protection also hinders the industrial application of organic silicon coupling agents. 
Therefore, the use of enzymes as biocatalysts in the surface processing of lignocellulosic polymers has increased dramatically in recent years [13-18]. Enzymatic processes have numerous advantages such as specificity, cost effective, eco-friendly, mild reaction conditions than the chemical methods. Laccases (EC 1.10.3.2, benzenediol:oxygen oxidoreductase) are the most investigated enzymes in this field. They are multicopper-containing zymoproteins that catalyze the monoelectronic oxidation of phenols or aromatic amines to reactive radical species and simultaneously reduce molecular oxygen to water in a redox reaction [19]. Lignin is a three-dimensional aromatic polymer with three structural units, guaiacyl, syringyl, and $p$-hydroxyphenyl, joined together in an irregular manner [20]. Studies have shown that lignin is a suitable substrate for laccase, and the phenolic sites of lignin molecules can be oxidized to phenoxyl radicals by laccase [21]. Using the laccase-catalyzed oxidation of the lignin moieties on the surface, lignocellulosic materials could be activated to create a radical-rich reactive surface, and oxidized phenol radicals were grafted on the surface for improving the surface properties or add new functions [22-24]. Jute fiber, a widely used lignocellulosic textile material with a lignin content of $14-20 \%$, can be modified to satisfy the demand of hydrophobicity in various textile industrial applications using this green biotechnology. Besides the use of phenolic monomers in enzymatic grafting reactions, Kudanga et al. first demonstrated the laccase-mediated coupling of amine monomers with long alkyl chains to lignin model molecules by LC-MS [25]. However, to the best of our knowledge, the hydrophobic surface functionalization of jute products by laccase-mediated grafting with alkylamines has not been attempted.

In this study, the feasibility of the laccase-facilitated grafting of octadecylamine (OA) molecules onto the jute surface was investigated to endow it with excellent hydrophobic property. The lignins isolated from jute fabrics were analyzed by matrix-assisted laser desorption/ionization time-of-flight mass spectrometry (MALDI-TOF MS), ${ }^{1} \mathrm{H}$ NMR, ${ }^{13} \mathrm{C}$ NMR, and heteronuclear single quantum correlation (HSQC)-NMR. The surface of the jute fabrics was characterized by FT-IR, X-ray photoelectron spectroscopy (XPS), and scanning electron microscopy (SEM). Then, the nitrogen content of the jute fabrics was measured by the microKjeldahl method, and the grafting percentage (Gp) and grafting efficiency (GE) were calculated. The surface hydrophobicity of the jute fabrics was estimated by contact angle and wetting time measurements. Further, the effects of OA concentration and incubation time on the grafting degree and jute hydrophobicity were investigated.

\section{Experimental}

\subsection{Materials and reagents}

Laccase from Trametes versicolor was provided by SigmaAldrich. The $100 \%$ raw jute fabric, with a $7 / 7$ (warp/weft) $\mathrm{cm}^{-1}$ yarn count, was supplied by Longtai weaving Co., Ltd (Changshu, China). OA (90\% purity) was obtained from Aladdin Technology Co. Ltd. (Shanghai, China). All the other chemicals used in this study were commercially available and analytical grade.

\subsection{Laccase assay}

The activity of laccase was measured using a UV-visible spectrophotometer by monitoring the oxidation of 2,2'-azino-bis(3-ethylthiazoline-6-sulfonate) (ABTS; $\varepsilon_{420}=36,000 \mathrm{M}^{-1} \times \mathrm{cm}^{-1}$ ) as the substrate at $420 \mathrm{~nm}$ in $80: 20(\mathrm{v} / \mathrm{v}, \%)$ acetate buffer $\mathrm{pH}$ $4 / \mathrm{EtOH}$ mixtures at $50^{\circ} \mathrm{C}$. The enzyme activity was expressed in units defined as micromoles of ABTS oxidized per minute [26].

\subsection{Pretreatment of jute fabrics}

The jute fabrics were Soxhlet-extracted with benzene/ethanol $(\mathrm{v} / \mathrm{v}, 2: 1)$ for $12 \mathrm{~h}$ to remove the lipophilic extractives and then refluxed in distilled water for $3 \mathrm{~h}$ to remove the water-soluble fractions. As a result, the oxidation of substrate molecules by laccase and the analysis of modified fabrics could be carried out without interference.

\subsection{Enzymatic grafting of $O A$ onto jute fabric surface}

The jute fabrics $(1 \mathrm{~g})$ were incubated in $50 \mathrm{~mL} \mathrm{80:20} \mathrm{(v/v, \% )}$ acetate buffer $\mathrm{pH} 4 / \mathrm{EtOH}$ solutions with $2.5 \mathrm{U} / \mathrm{mL}$ laccase and $5 \mathrm{mM}$ $\mathrm{OA}$. The reaction was carried out at $50^{\circ} \mathrm{C}$ for $4 \mathrm{~h}$ in a shaking bath. Then, the fabrics were washed twice with distilled water at $50^{\circ} \mathrm{C}$ for $20 \mathrm{~min}$ and then extracted with benzene/ethanol $(\mathrm{v} / \mathrm{v}, 2: 1)$ for $12 \mathrm{~h}$ to remove the unreacted absorbed OA monomers. The control and laccase-treated samples were treated similarly as mentioned above.

\subsection{Isolation of lignin from jute fabrics}

The residual lignins in various treated jute fabric samples were separated using the method reported by Evtuguin et al. [27] and then purified as described by Lundquist et al. [28].

\subsection{Characterization of lignin isolated from jute fabrics}

\subsubsection{MALDI-TOF-MS analysis}

MALDI-TOF MS measurements of lignins were performed using a Bruker ultrafleXtreme MALDI-TOF mass spectrometer (Bremen, Germany) equipped with a nitrogen laser $(\lambda=337 \mathrm{~nm})$. The lignin samples were dissolved in $\mathrm{N}, \mathrm{N}$-dimethylformamide (DMF) with a concentration of $1 \mathrm{mg} / \mathrm{mL}$. Sinapinic acid (SA) was selected as the matrix compound (saturated in TA 30 solution containing 30\% acetonitrile and $0.1 \%$ tetrahydrofuran) as it was proven to give better results for lignin analysis compared to other matrices such as 2,5-dihydroxybenzoic acid (DHB) [29]. The sample/matrix mixture ( $2 \mu \mathrm{L}, \mathrm{v} / \mathrm{v}, 1: 1)$ was deposited on the MALDI target plate and allowed to dry at room temperature in air. The positive-ion mass spectra were acquired from the dried sample spots in reflective mode.

\subsubsection{NMR analysis}

The isolated lignins were acetylated using the method proposed by Jahan et al. [30] before the NMR measurements. The ${ }^{1} \mathrm{H}$ NMR, ${ }^{13} \mathrm{C}$ NMR, and HSQC 2D-NMR spectra of $50 \mathrm{mg}$ acetylated lignins and $25 \mathrm{mg}$ OA monomer dissolved in $500 \mu \mathrm{L}$ deuterated chloroform $\left(\mathrm{CDCl}_{3}\right)$ were recorded using a Bruker AVANCE $400 \mathrm{MHz}$ spectrometer.

\subsection{Characterization of jute fabrics}

\subsubsection{FT-IR analysis}

The FT-IR analysis of jute fabrics was performed using a Nicolet iS10 FT-IR spectrometer (Thermo Fisher Scientific, USA) with the ATR technique. The spectra were recorded in the range $4000-650 \mathrm{~cm}^{-1}$ at $4 \mathrm{~cm}^{-1}$ resolution and 16 scans per sample.

\subsubsection{XPS analysis}

The XPS experiments of jute fabrics were performed using a RBD upgraded PHI-5000 C ESCA system (Perkin Elmer) with MgK $\alpha$ radiation $(h v=1253.6 \mathrm{eV})$. The X-ray anode was run at $250 \mathrm{~W}$, and the high voltage was maintained at $14.0 \mathrm{kV}$ with a detection angle of $54^{\circ}$. Both the entire spectra $(0-1100 \mathrm{eV})$ and the narrow spectra of carbon with significantly higher resolution were recorded using the RBD 147 interface (RBD Enterprises, USA) and the AugerScan 
3.21 software. The binding energies were calibrated with the contaminant carbon $(\mathrm{C} 1 \mathrm{~s}=284.6 \mathrm{eV})$. The spectrum analysis including background subtraction, deconvolution, integration, and quantitation was carried out by using the RBD AugerScan 3.21 software.

\subsubsection{SEM analysis}

The surface of the jute fabric samples was scanned using a SU1510 SEM (Hitachi, Japan) under $5.00 \mathrm{kV}$ at $1.00 \mathrm{k}$ magnification.

\subsection{Quantitative estimation of OA-grafting onto jute fabrics}

The nitrogen content of the jute fabric samples was determined using the micro-Kjeldahl method. The Gp and GE of OA monomers on jute fabrics were calculated from the total nitrogen content of the samples using the following equations:

$\mathrm{Gp}(\%)=\frac{\left(N_{g}-N_{c}\right) \times M_{\mathrm{C}_{18} \mathrm{H}_{39} \mathrm{~N}}}{14}$

$\mathrm{GE}(\%)=\frac{\left(N_{g}-N_{c}\right) \times 10^{3}}{14 \times 0.05 \times C}$

where $N_{g}$ is the nitrogen content of the grafted jute fabric (\%), $N_{c}$ is the nitrogen content of the control jute fabric (\%), $C$ is the molar concentration of $\mathrm{OA}$ in the grafting reaction $(\mathrm{mM})$, and $M$ is the molar mass of OA $(\mathrm{g} / \mathrm{mol})$.

\subsection{Hydrophobicity measurement of jute fabrics}

The hydrophobicity of the jute fabrics was assessed by the contact angle and wetting time. Before the measurements, the jute fabric samples were brought to moisture equilibrium in a standard atmosphere with a relative humidity of $65 \pm 5 \%$ at $21 \pm 1^{\circ} \mathrm{C}$. Then, the contact angle was measured using a JC2000D4 contact angle meter (Zhongchen, Shanghai). For each sample, five spots were measured, and the results were averaged.

The wetting time was measured according to the AATCC Test Method 79-2007. A drop of water was allowed to fall from a height of $10 \pm 1 \mathrm{~mm}$ onto the taut surface of the test fabric. The time required for the specular reflectance of the water drop to disappear was measured and recorded as the wetting time. Five readings were taken and averaged for each sample.

\subsection{Optimization of the grafting process}

The two most important parameters in the laccase-mediated grafting process, OA concentration and incubation time, were optimized. The grafting degree was estimated by the Gp and GE of the reaction as well as the contact angle and wetting time of the jute fabrics.

The enzymatic grafting process for the optimization of OA concentration was carried out at $50^{\circ} \mathrm{C}$ for $4 \mathrm{~h}$ with OA concentration ranging from $0 \mathrm{mM}$ to $25 \mathrm{mM}$ and $2.5 \mathrm{U} / \mathrm{mL}$ laccase in $\mathrm{pH} 4,0.2 \mathrm{M}$ acetate buffer/ethanol medium (80:20, v/v, \%). For the optimization of incubation time, periods of $0,2,4,12$, and $24 \mathrm{~h}$ were tested with an $\mathrm{OA}$ concentration of $5 \mathrm{mM}$. The other incubation procedure was the same as described in the optimization of OA concentration.

\section{Results and discussion}

\subsection{Spectral analysis of isolated lignins from jute fabrics}

In this study, the laccase-mediated grafting reaction of lignocellulosic jute fabrics with amino-containing OA monomers was conducted to increase the surface hydrophobicity of the jute fabrics. To obtain the detailed structural information of the grafting products, the residual lignin in the jute fabrics was isolated by liquid extraction and further analyzed in the macromolecular level by MALDI-TOF MS and NMRs ( ${ }^{1} \mathrm{H}$ NMR, ${ }^{13} \mathrm{C}$ NMR, and HSQC-NMR).

\subsubsection{MALDI-TOF MS analysis}

The MALDI-TOF mass spectra of the lignins isolated from laccase/OA-treated, laccase-treated, and control jute fabrics are shown in Fig. 1, and all the peaks in the mass spectra are listed in Table 1. A broad molecular weight distribution from 200 Da to more than 1000 Da was evident. The spectra indicated a fine oligomeric structure, which can be attributed to the different degrees of oligomerization, from dimers to pentamers. The molecular weights of the dimers, trimers, tetramers, pentamers, and hexamers were in the range 305-529 Da, 655-733 Da (expansion on the left side to $595 \mathrm{Da}$ for the lignin isolated from laccase-treated jute), 867-973 Da (additional 793 Da for the control sample), 1141-1197 Da, and 1421-1443 Da, respectively. An additional hyperfine structure, which was assigned to different oligomeric molecules with the same degree of polymerization (DP), was superimposed on the oligomeric lignin signals. These mass spectra showed a similar structure as that obtained by Bocchini et al. for milled bamboo lignin in which a wide molecular weight distribution from 200 to almost 1000 with pronounced fine and hyperfine structures was reported [29]. The sequences of signals for the oligomers with the same DP were characterized by a $\Delta m$ of $14-18$ mass units, possibly because of different linkages between the phenylpropane units and a different number of oxygen atoms in the lignin oligomeric structures. In the MALDI-TOF mass spectrum ions of milled jute lignins, $m / z 358$, 393,429 , and 457 for the dimers can be related to non-methylated HG, GG, GS, and SS units, and $m / z$ 346, 372, 409, 441, and 469 can be related to methylated HH, HG, HS/GG, GS, and SS units. Similar assignments can be made for the other oligomeric structures, such as SSS at $m / z 693$ and SSSS at $m / z$ 917. The gap between some oligomers with different DPs was consistent for $m / z 224$, such as 447/671/895, 487/711/935, 509/733/957, 469/693/917/1141, and $973 / 1197 / 1421$, which was considered as the molecular weight of the non-methylated $S$ phenylpropane unit of lignin according to the study of Bocchini et al. [29]. The results, which were evident and common throughout the MALDI-TOF mass spectra, indicate that numerous oligomeric structures with a higher DP were the adducts of $\mathrm{S}$ units and the corresponding oligomers with a lower DP.

The MALDI-TOF mass spectrum of the lignin from the laccase/OA-treated jute fabrics showed some new ions compared to the other two samples at $m / z 546,557,560,574,588,602,618$, and 646 (between dimers and trimers) and $m / z 770,781,798,812$, and 826 (between trimers and tetramers). Among the former signals, $m / z 574,588,602,618$, and 646 were the sum of the molecular weight of OA (269.5 Da) and $m / z 305,318,332,346$, and 376 for the dimers exactly or approximately, characterizing the grafting products of the lignin dimers with OA monomers. The smaller peaks ( $m / z 546,557$, and 560), which may also correspond to the grafting structures, showed no corresponding dimers or monomers because the assignment of signals below $m / z 300$ was interfered by the mass spectrum ions of the matrix. The latter group of data was calculated as the sum of $224 \mathrm{Da}$ (Mw of S unit) and $m / z 546,557,574,588$, and 602 in the former data, representing the adducts of $S$ units and the corresponding grafting structures of the dimers with $\mathrm{OA}$.

\subsubsection{NMR analysis}

The HSQC 2D-NMR spectra of the OA monomers and lignins from various treated jute fabrics are shown in Fig. 2. The HSQC NMR spectra of the jute lignins showed three main regions corresponding to aromatic $\left(\delta_{\mathrm{H}} / \delta_{\mathrm{C}} 5.5-8 / 95-135 \mathrm{ppm}\right)$, oxygenated aliphatic $\left(\delta_{\mathrm{H}} / \delta_{\mathrm{C}} 2.5-6.5 / 50-95 \mathrm{ppm}\right)$, and non-oxygenated aliphatic $\left(\delta_{\mathrm{H}} / \delta_{\mathrm{C}}\right.$ 


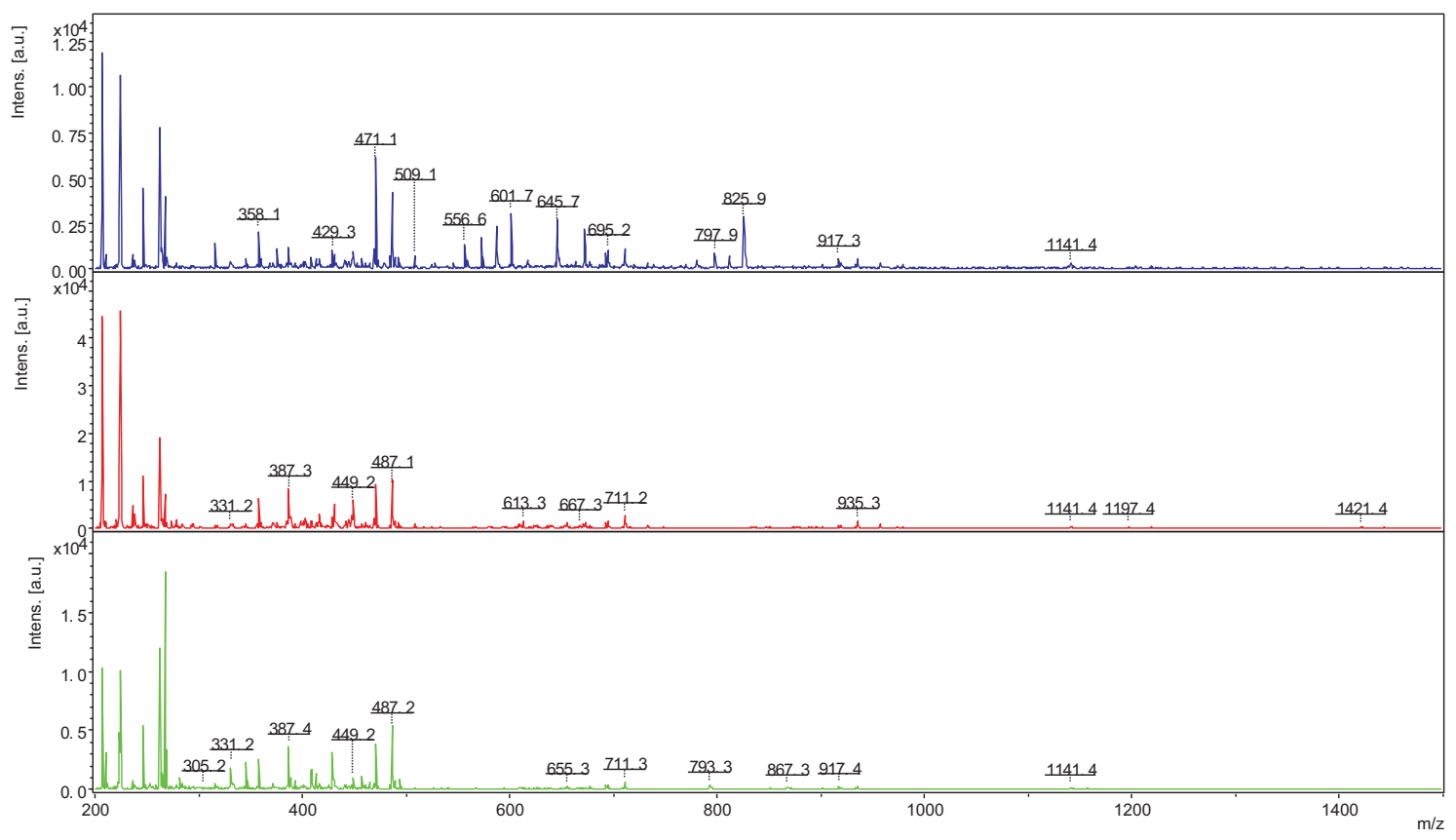

Fig. 1. MALDI-TOF mass spectra of lignin samples isolated from various treated jute fabrics.

0-3/0-50 ppm) ${ }^{1} \mathrm{H}-{ }^{13} \mathrm{C}$ correlations [20,31]. Several new crosssignals with $\delta_{\mathrm{H}} / \delta_{\mathrm{C}} 1.25 / 32.51,1.28 / 29.53$, and $1.26 / 22.55 \mathrm{ppm}$ and $\delta_{\mathrm{H}} / \delta_{\mathrm{C}} 0.88 / 13.99 \mathrm{ppm}$ were observed in the HSQC spectrum of lignin isolated from the laccase/OA-treated jute fabrics compared to those of the other lignin samples. These cross-signals also appeared in the HSQC spectrum of OA monomers with similar $\delta_{\mathrm{H}} / \delta_{\mathrm{C}}$ positions $(1.24 / 32.51,1.26 / 29.46,1.25 / 22.65$, and $0.88 / 13.95 \mathrm{ppm})$, corresponding to the $\mathrm{H}-\mathrm{C}$ correlations in the methylene groups with different chemical environments and in the methyl group, respectively.

In the ${ }^{1} \mathrm{H}$ NMR (Fig. 3) and ${ }^{13} \mathrm{C} \mathrm{NMR} \mathrm{(Fig.} \mathrm{4)} \mathrm{spectra} \mathrm{of} \mathrm{the} \mathrm{lignin}$ from the laccase/OA-treated jute fabrics, the ${ }^{1} \mathrm{H}$ and ${ }^{13} \mathrm{C}$ signals of the methylene groups were observed at $\delta 1.25 \mathrm{ppm}$ and $\delta 31.91$, $29.69,29.35,22.68 \mathrm{ppm}$, respectively. In contrast, new peaks corresponding to the methyl groups appeared at $\delta 0.88 \mathrm{ppm}$ in the
${ }^{1} \mathrm{H}$ NMR spectrum and at $\delta 14.12 \mathrm{ppm}$ in the ${ }^{13} \mathrm{C}$ NMR spectrum. These results indicate that the OA monomers containing long alkyl chains were attached to the lignin structures of jute fabrics by the reactions mediated by laccase.

\subsection{Surface analysis of jute fabrics}

\subsubsection{FT-IR analysis}

Fig. 5 shows the ATR-IR spectra of the control, laccasetreated, and laccase/OA-treated jute fabric samples in the range $4000-2500 \mathrm{~cm}^{-1}$. In contrast to the other samples, the spectrum of the laccase $/ O A$-treated jute fabric had a weak peak at $3333 \mathrm{~cm}^{-1}$, corresponding to the $\mathrm{O}-\mathrm{H}$ stretching vibration. Moreover, the saturated $\mathrm{C}-\mathrm{H}$ stretching vibration at $2898 \mathrm{~cm}^{-1}$ was divided into two peaks at $2922 \mathrm{~cm}^{-1}$ and $2853 \mathrm{~cm}^{-1}$ in the IR spectrum of

Table 1

Total peaks in the MALDI-TOF mass spectra of lignin samples isolated from different treated jute fabrics.

\begin{tabular}{|c|c|c|}
\hline Samples & Total peaks a & red in the MALDI-TOF-MS spectra \\
\hline $\begin{array}{l}\text { Lignin from } \\
\text { laccase/OA } \\
\text { treated jute }\end{array}$ & $\begin{array}{l}\text { Dimers } \\
\text { Dimers }+ \text { OA } \\
\text { Trimers } \\
\text { Trimers + OA } \\
\text { Tetramers } \\
\text { Pentamers }\end{array}$ & $\begin{array}{l}316.1 ; 331.2 ; 332.3 ; 346.2 ; 358.1 ; 360.3 ; 368.4 ; 372.1 ; 376.3 ; 385.1 ; 386.1 ; 387.1 ; 387.3 ; 389.1 ; 393.3 ; 399.1 ; 401.1 ; 403.1 ; \\
409.3 ; 413.3 ; 415.1 ; 417.1 ; 429.3 ; 431.1 ; 433.2 ; 441.1 ; 441.3 ; 443.1 ; 445.2 ; 447.1 ; 448.2 ; 449.2 ; 449.4 ; 453.1 ; 457.3 ; 461.2 ; \\
465.4 ; 469.1 ; 471.1 ; 479.5 ; 487.1 ; 493.1 ; 494.6 ; 509.1 ; 525.1 ; 528.6 \\
545.6 ; 556.6 ; 559.6 ; 573.6 ; 587.7 ; 601.7 ; 617.6 ; 645.7 ; \\
659.7 ; 663.7 ; 672.7 ; 677.2 ; 686.7 ; 693.2 ; 695.2 ; 709.2 ; 711.2 ; 719.7 ; 733.2 \\
769.9 ; 780.9 ; 797.9 ; 811.9 ; 825.9 \\
917.3 ; 919.3 ; 933.3 ; 935.3 ; 957.3 \\
1141.4\end{array}$ \\
\hline $\begin{array}{l}\text { Lignin from } \\
\text { laccase-treated } \\
\text { jute }\end{array}$ & $\begin{array}{l}\text { Dimers } \\
\text { Trimers } \\
\text { Tetramers } \\
\text { Pentamers } \\
\text { Hexamers }\end{array}$ & 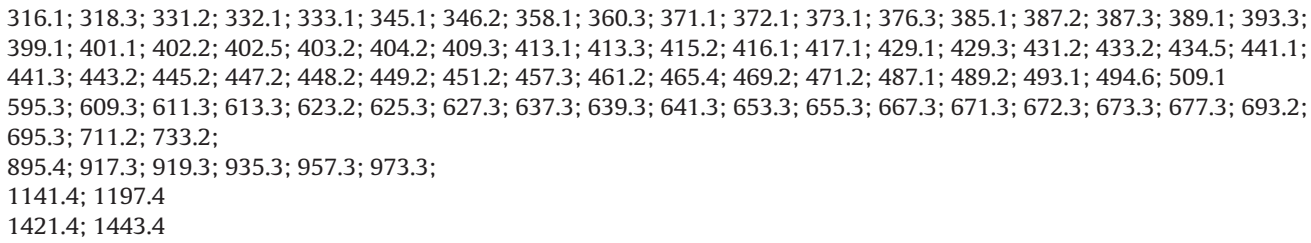 \\
\hline $\begin{array}{l}\text { Lignin from } \\
\text { control jute }\end{array}$ & $\begin{array}{l}\text { Dimers } \\
\text { Trimers } \\
\text { Tetramers } \\
\text { Pentamers }\end{array}$ & $\begin{array}{l}305.2 ; 316.1 ; 319.2 ; 331.2 ; 333.3 ; 334.0 ; 346.3 ; 347.3 ; 358.2 ; 372.1 ; 385.2 ; 387.4 ; 393.3 ; 401.2 ; 402.2 ; 409.3 ; 413.3 ; 417.2 ; \\
425.3 ; 429.3 ; 431.2 ; 433.2 ; 441.2 ; 441.4 ; 443.2 ; 447.2 ; 448.2 ; 449.2 ; 449.4 ; 457.3 ; 461.2 ; 465.4 ; 469.2 ; 471.2 ; 487.2 ; 489.2 ; \\
494.6 \\
655.3 ; 693.3 ; 695.3 ; 711.3 \\
793.3 ; 867.3 ; 917.4 ; 935.3 \\
1141.4\end{array}$ \\
\hline
\end{tabular}



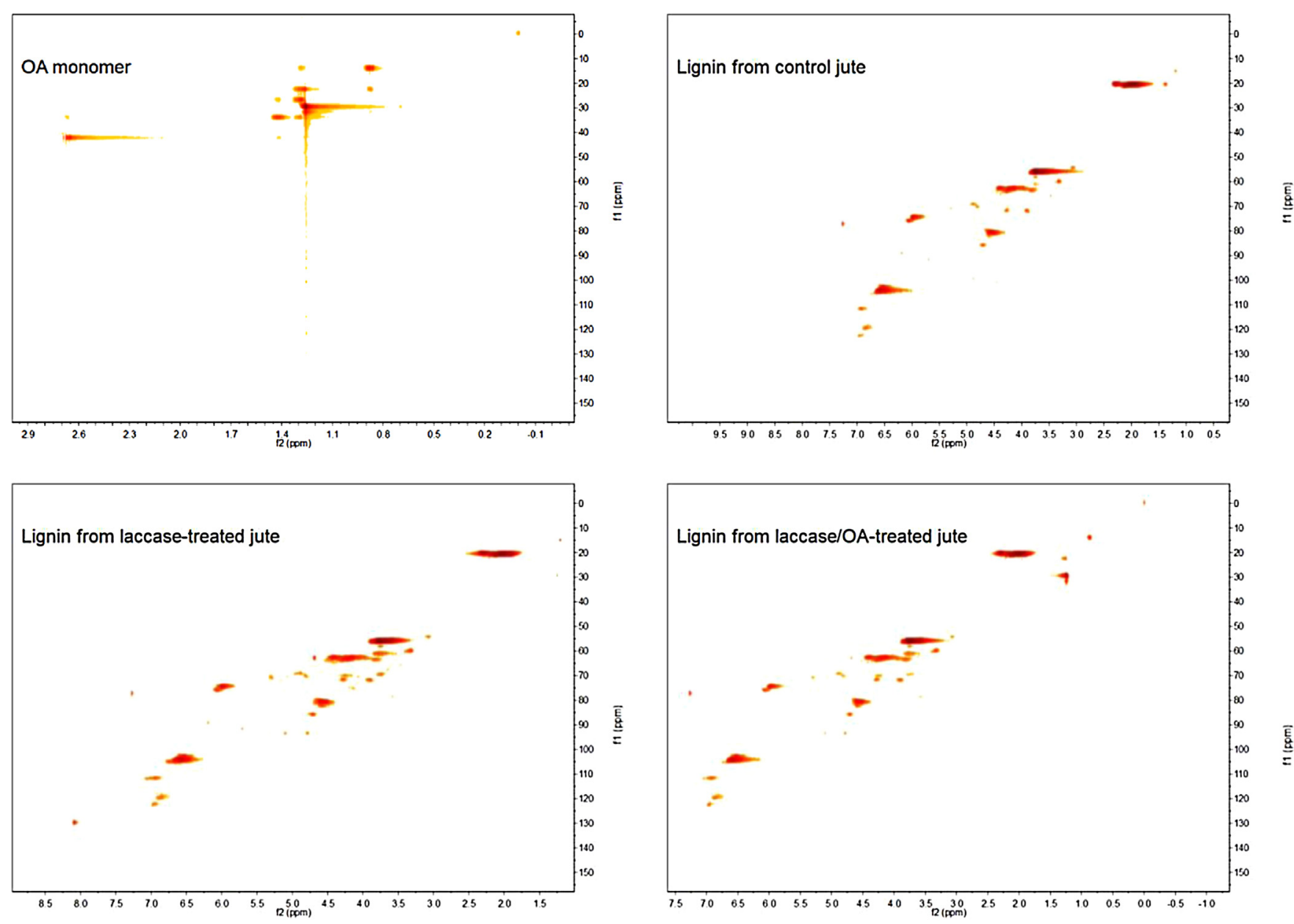

Fig. 2. HSQC-NMR spectra of lignin samples isolated from various treated jute fabrics.

the laccase/OA-treated jute fabric. The two new peaks can be attributed to be the characteristic vibrations of the methylene groups $\left(\mathrm{C}-\mathrm{CH}_{2}-\mathrm{C}\right)[32]$. The spectral comparison of the laccase/OAtreated jute fabric with the other samples indicated that some phenolic hydroxyl groups of the lignin moieties on the jute surface may have been consumed as the grafting sites, and the long methylene chains of OA were incorporated into the jute surface by the laccase/OA treatment.

\subsubsection{XPS analysis}

Besides the FT-IR spectroscopy analysis, XPS spectroscopy was studied to better understand the changes in the surface chemistry of jute fabrics after the laccase/OA treatment. The deconvolution of the C1s high-resolution signals in the XPS spectra was carried out by curve fitting to obtain the bonding states of carbon on the jute surface.

The $\mathrm{C} 1 \mathrm{~s}$ spectra were deconvoluted into three peaks, C1, C2, and C3, as shown in Fig. 6. According to the literature [33], The C3 peak with the lowest binding energy represents a carbon atom linked only to carbon or hydrogen atoms $(-\mathrm{C}-\mathrm{C} /-\mathrm{C}-\mathrm{H})$. The $\mathrm{C} 2$ peak represents a carbon atom bound to a non-carbonyl oxygen atom $(-\mathrm{C}-\mathrm{OH} /-\mathrm{C}-\mathrm{O}-\mathrm{C})$. The $\mathrm{C} 1$ peak with the highest binding energy represents a carbon atom bound to one carbonyl oxygen atom $(-\mathrm{C}=\mathrm{O})$ or two non-carbonyl oxygen atoms $(\mathrm{O}-\mathrm{C}-\mathrm{O})$. The proportions and binding energy positions of these groups are shown in Table 2. The C1 peak intensity on the jute surface increased from $43.12 \%$ to $46.68 \%$ after the laccase treatment, because of the adsorbed laccase traces rich in $\mathrm{O}=\mathrm{C}-\mathrm{NH}-$ groups. An evident increase in the C3 peak intensity from $21.99 \%$ (the control jute surface) to $30.15 \%$ (the laccase/OA-treated jute surface) was observed as well as a decrease in the $\mathrm{C} 1$ peak intensity from $43.12 \%$ of the control jute to $34.78 \%$ of the laccase/OA-treated jute. The decrease in the $\mathrm{C} 1$ peak intensity can be attributed to the grafting of $\mathrm{OA}$ monomers on jute surface leading to a decrease in the $\mathrm{O}-\mathrm{C}-\mathrm{O}$ structure, which was only present in the cellulose component of jute fibers. The changes in the proportion of the $-\mathrm{C}-\mathrm{C} /-\mathrm{C}-\mathrm{H}$ groups in the $\mathrm{C} 1 \mathrm{~s}$ spectra directly indicated that $\mathrm{OA}$ molecules with long alkyl chains were incorporated onto the jute surface by the laccasemediated grafting reactions.

\subsubsection{SEM analysis}

The surface morphologies of the control, laccase-treated, and laccase/OA-treated jute fabrics were analyzed by SEM. The control jute surface was rough with some natural impurities such as lignin and pectin (Fig. 7a). After the laccase treatment, the surface of the jute fibers became smooth and neat (Fig. 7b), probably because of the enzymatic dislodgement of the lignin on the surface. At the beginning of the laccase treatment, some lignins on the jute fibers were first degraded into low-molecular-weight pieces and then dissolved in the aqueous medium. In the later stage of the reaction, the laccase-mediated polymerization of lignin became predominant, and the dissolved lignin was covalently attached back to the jute surface [34]. The degradation and subsequent polymerization of lignin by laccase catalysis redistributed the lignin on the jute surface and made the jute surface glossy. The surface of the laccase/OA-treated jute samples contained multitudinous small 


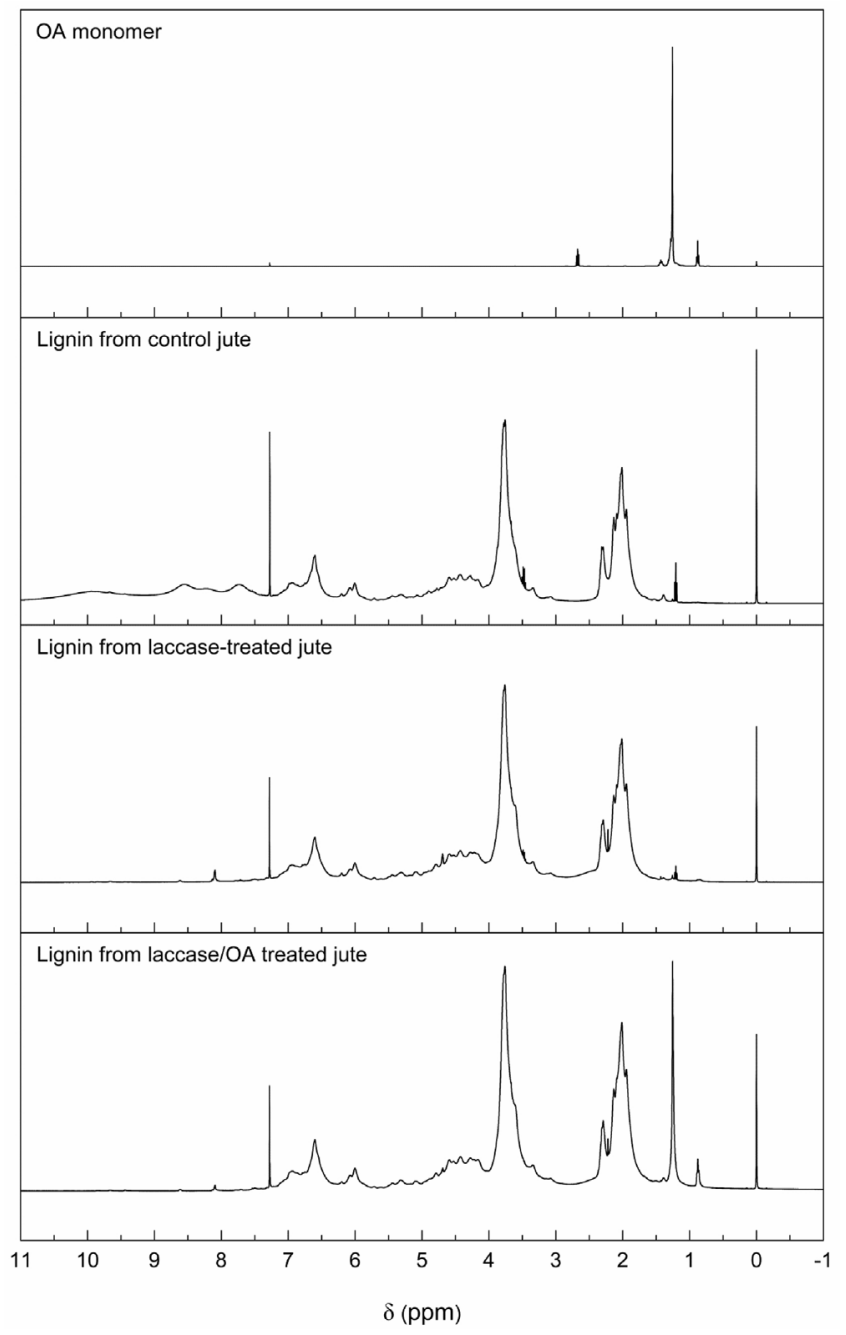

Fig. 3. ${ }^{1} \mathrm{H}$ NMR spectra of lignin samples isolated from various treated jute fabrics.

flakes as shown in Fig. 7c. These particulates on the laccase/OAtreated jute surface can be regarded as the aggregates of OA molecules attached by the covalent grafting reaction.

\subsection{Proposed enzymatic grafting mechanism of $O A$ on jute surface}

The bulk jute fiber is composed of approximately $58-63 \%$ cellulose, $20-24 \%$ hemicellulose, and $12-15 \%$ lignin [35]. The lignin component is mostly composed of guaiacyl and syringyl units with few $p$-hydroxyphenyl units [20]. It is well known that a jute fiber consists of three distinct layers, i.e., middle lamella, primary cell wall, and secondary cell wall. The surface of the jute fiber (mainly the middle lamellae) is primarily composed of pectin and lignin [36]. The laccase-mediated OA-grafting to the lignin molecules on jute surface was surmised according to the relevant literatures $[25,37]$ and above results and shown in Fig. 8. In general, the laccase-mediated grafting of phenolic monomers onto lignocellulosic materials has been successfully achieved to endow such polymers with novel functions [13,16,17]. However, the homopolymerization of these phenolic monomers occurs inevitably along with the desired enzymatic grafting reactions. In contrast, the amine compounds such as OA used in this study are not polymerized or self-coupled by laccase; therefore, amines, not phenols, are ideal monomers for the enzymatic grafting modification of natural lignocellulosic polymers.

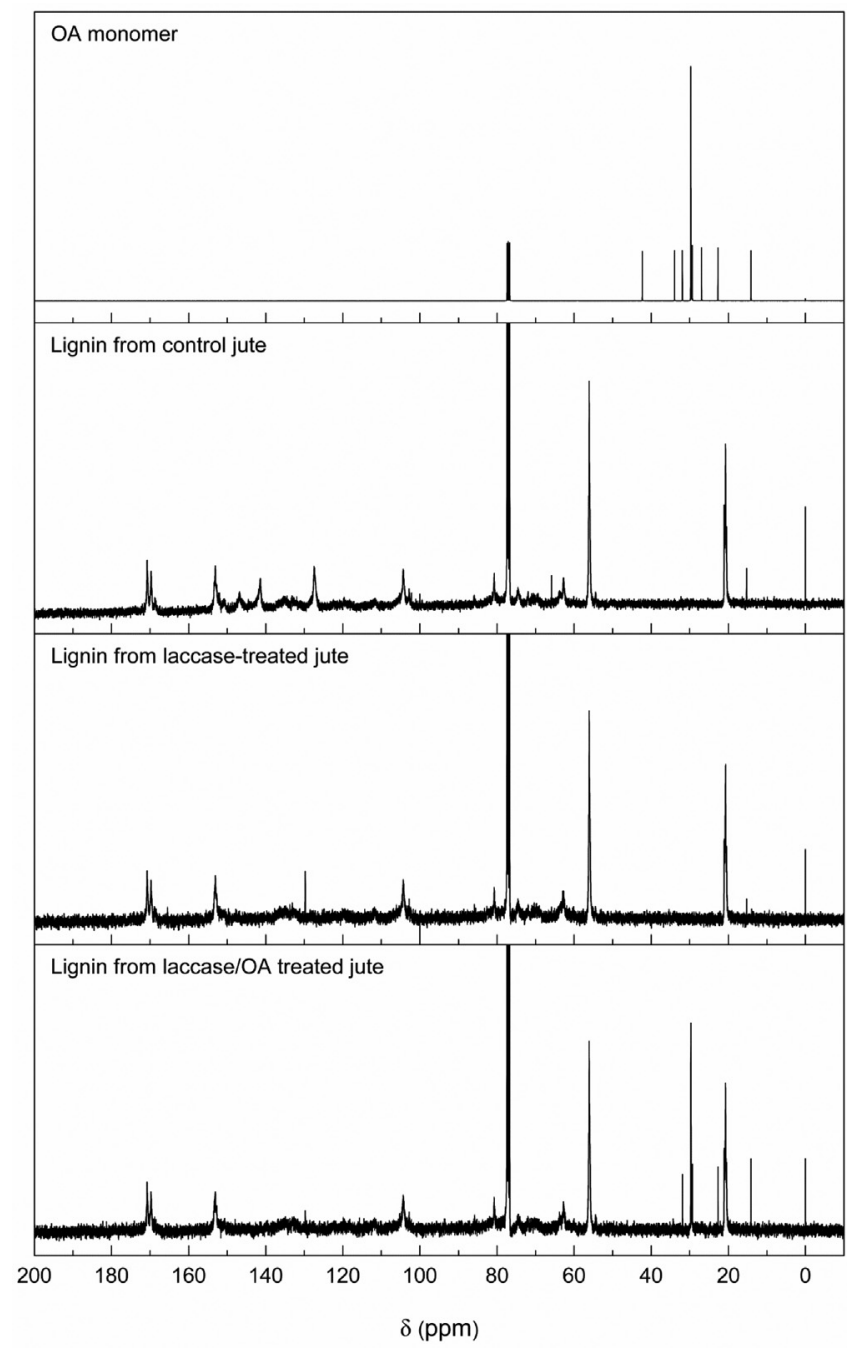

Fig. 4. ${ }^{13} \mathrm{C}$ NMR spectra of lignin samples isolated from various treated jute fabrics.

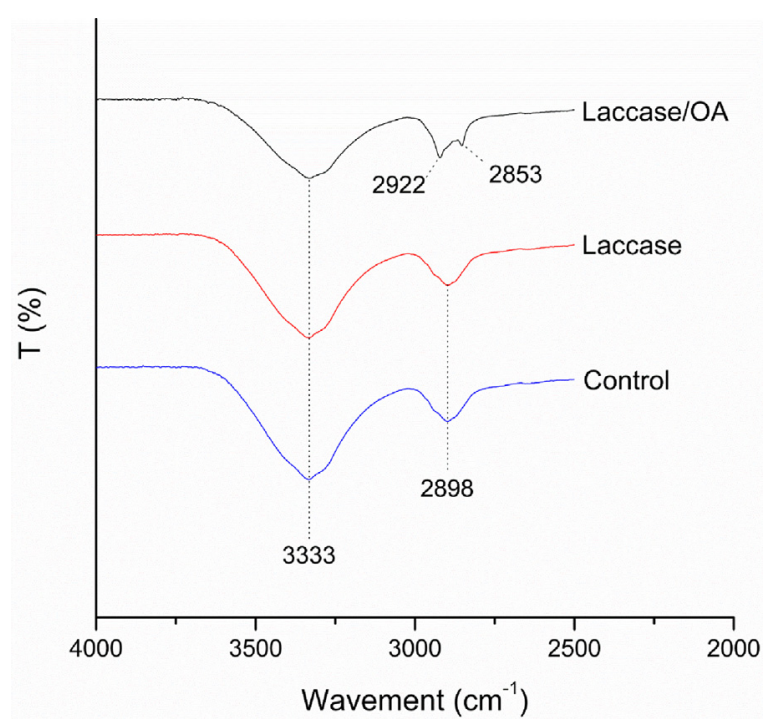

Fig. 5. FT-IR spectra of control jute fabric (Control), laccase-treated jute fabric (Laccase) and laccase/OA-treated jute fabric (Laccase/OA). 

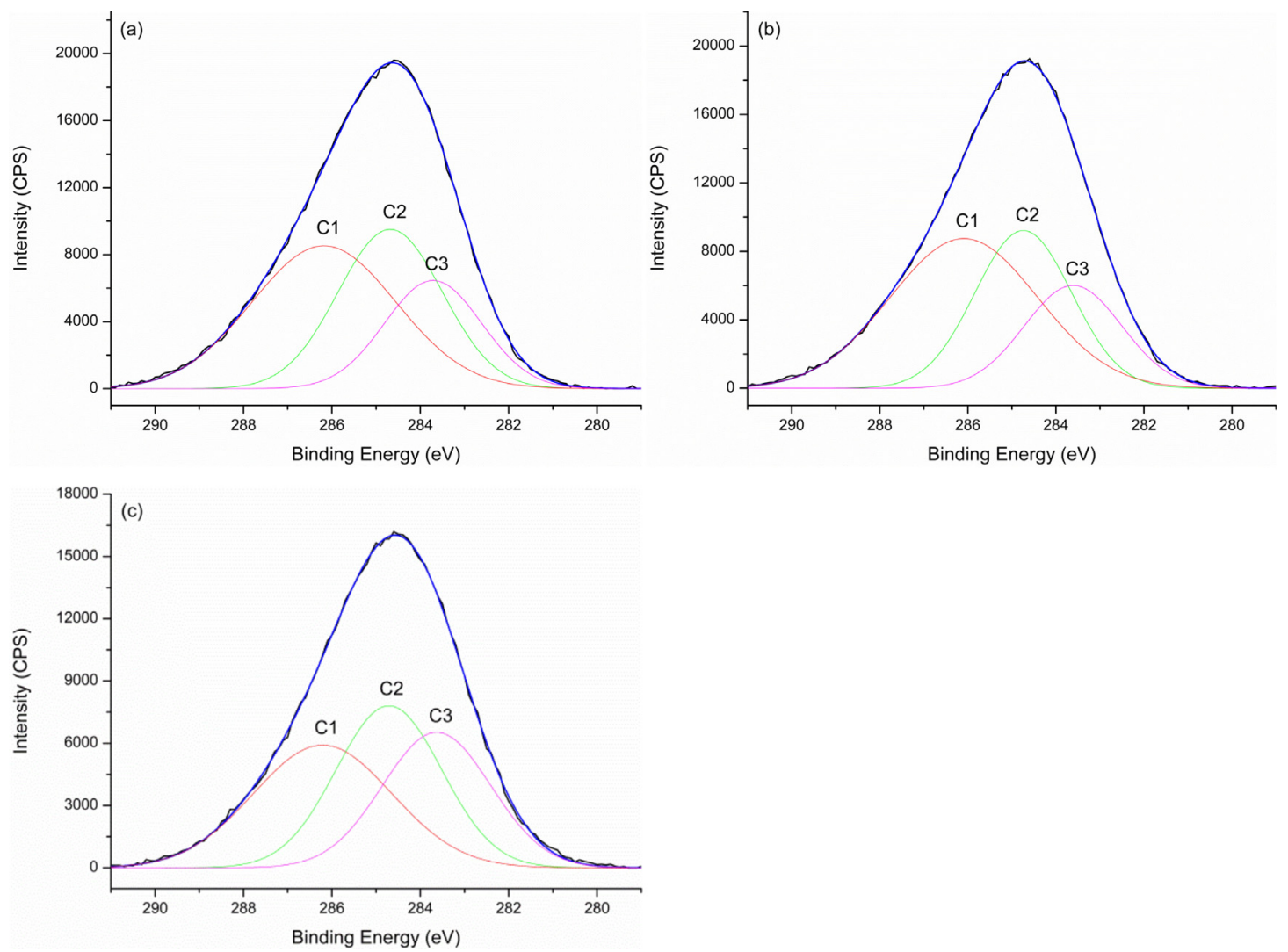

Fig. 6. Deconvoluted C1s spectra of control jute fabric (a), laccase-treated jute fabric (b) and laccase/OA-treated jute fabric (c).
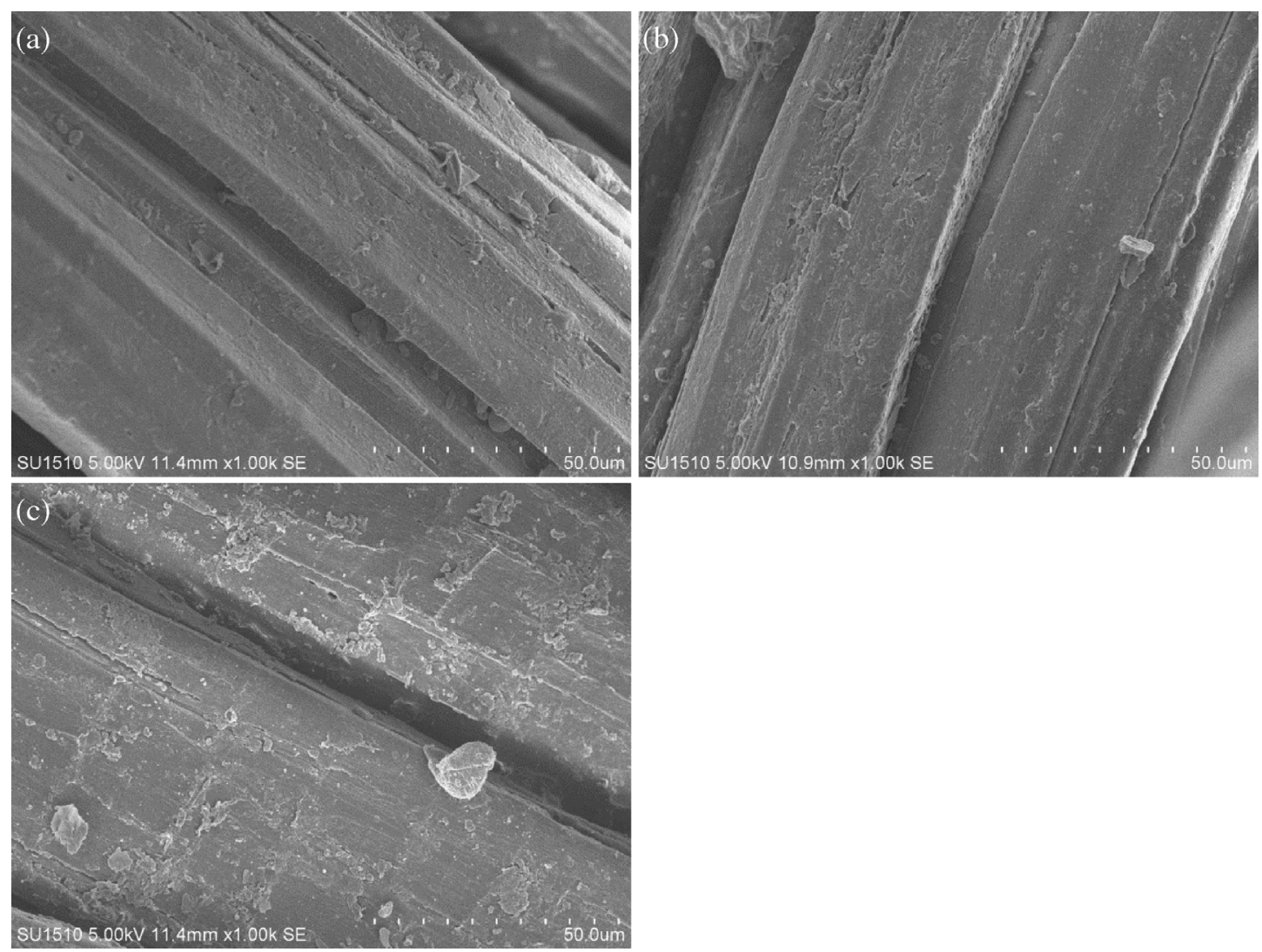

Fig. 7. SEM images of control jute fabric (a), laccase-treated jute fabric (b) and laccase/OA-treated jute fabric (c) amplified at $1.00 \mathrm{k}$. 
Table 2

Proportions and assignments of deconvoluted C1s peaks on the surface of various jute samples.

\begin{tabular}{|c|c|c|c|c|c|c|}
\hline \multirow{2}{*}{$\begin{array}{l}\text { Carbon type } \\
\text { Samples }\end{array}$} & \multicolumn{2}{|c|}{$\mathrm{C} 1\left(-\mathrm{C}^{*}=\mathrm{O} / \mathrm{O}-\mathrm{C}^{*}-\mathrm{O}\right)$} & \multicolumn{2}{|c|}{$\mathrm{C} 2\left(-\mathrm{C}^{*}-\mathrm{OH} /-\mathrm{C}^{*}-\mathrm{O}-\mathrm{C}\right)$} & \multicolumn{2}{|c|}{$\mathrm{C} 3\left(-\mathrm{C}^{*}-\mathrm{C} /-\mathrm{C}^{*}-\mathrm{H}\right)$} \\
\hline & $\mathrm{BE}(\mathrm{eV})$ & Area (\%) & $\mathrm{BE}(\mathrm{eV})$ & Area (\%) & $\mathrm{BE}(\mathrm{eV})$ & Area (\%) \\
\hline Control jute & 286.18 & 43.12 & 284.68 & 34.89 & 283.71 & 21.99 \\
\hline Laccase treated jute & 286.09 & 46.68 & 284.74 & 32.13 & 283.61 & 21.19 \\
\hline Laccase/OA treated jute & 286.21 & 34.78 & 284.71 & 35.06 & 283.63 & 30.15 \\
\hline
\end{tabular}

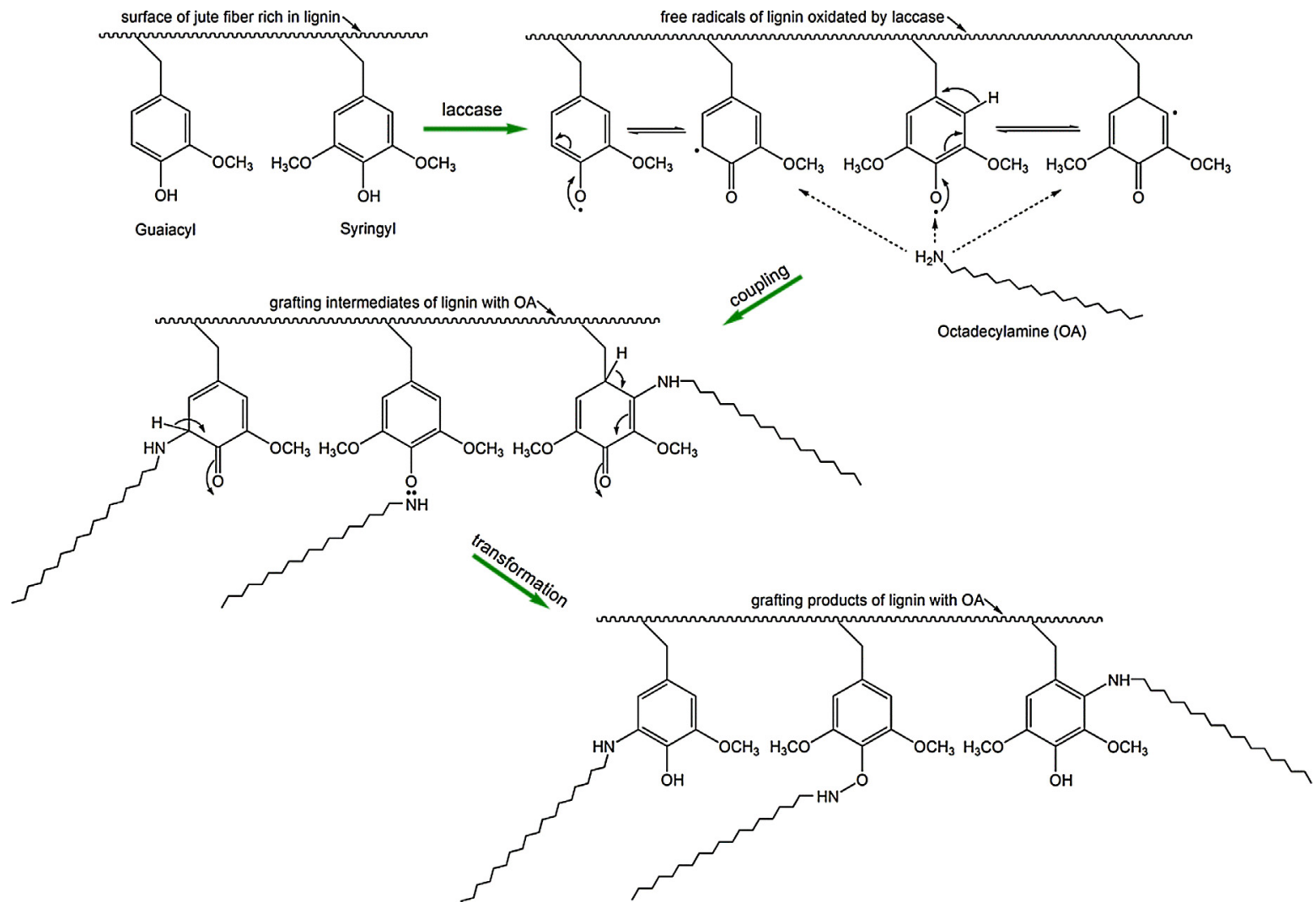

Fig. 8. The proposed pathway of the OA-grafting reaction to lignin moieties on the jute surface mediated by laccase.

Table 3

Nitrogen content of various jute fabric samples and grafting percentage (Gp), grafting efficiency (GE) of the laccase/OA treatments.

\begin{tabular}{lrll}
\hline Samples & \multicolumn{1}{l}{ Lac/OA } & Lac & Control \\
\hline $\mathrm{N}(\%)$ & $0.374 \pm 0.000$ & $0.336 \pm 0.001$ & $0.337 \pm 0.002$ \\
$\mathrm{Gp}(\%)$ & $0.712 \pm 0.039$ & - & - \\
$\mathrm{GE}(\%)$ & $10.571 \pm 0.571$ & - & -
\end{tabular}

\subsection{Quantification of OA-grafting onto jute fabrics}

The bulk nitrogen content of the jute fabrics was measured by the micro-Kjeldahl method, and the Gp and GE of the OA-grafting onto the jute fabrics were calculated. The nitrogen content of various jute fabric samples and the Gp and GE of the grafting reaction are listed in Table 3 . The total nitrogen content of the laccasetreated jute fabrics was almost the same as that of the control samples. In contrast, the bulk nitrogen content of the laccase/OAtreated jute fabrics increased by $0.037 \%$. Using Eqs. (1) and (2), the Gp and GE of the OA-grafting reaction under certain treatment conditions mediated by laccase were calculated to be $0.712 \%$ and $10.571 \%$, respectively.

\subsection{Effect of OA-grafting on the hydrophobicity of jute fabrics}

The contact angle and wetting time of water were used to assess the surface hydrophobicity of jute fabrics, and the results are shown in Table 4. The original jute fibers which were not pretreated have some surface hydrophobicity due to the existence of lipid and wax. After the extraction, the jute fiber became very hydrophibic as the wetting time of within $4 \mathrm{~s}$. The contact angle and the wetting time of the original jute fibers were $110.82^{\circ}$ and $10 \mathrm{~min}$ in average, respectively. For the laccase-treated jute fabrics, the water droplets on the surface disappeared with no specular reflectance in $4 \mathrm{~s}$. The laccase/OA-treated samples showed a much larger contact angle $\left(116.72^{\circ} \pm 9.24^{\circ}\right)$ and a longer wetting time $(18.5 \pm 2.5 \mathrm{~min})$. The increase in the hydrophobicity of the jute fabrics after the laccase/OA treatment supported that $\mathrm{OA}$ molecules with nonpolar alkyl chains were grafted onto the jute fabric surface mediated by laccase.

\subsection{Effect of grafting conditions on grafting degree and hydrophobicity}

The effects of OA concentration on the grafting degree of the OA-grafting reaction and the hydrophobicity of jute fabrics were investigated, and the results are shown in Fig. 9. With the increase 
Table 4

The contact angle and the wetting time of various treated jute fabrics.

\begin{tabular}{|c|c|c|c|c|}
\hline Jute fabric samples & Unpretreared & Laccase/OA & Laccase & Control \\
\hline Contact angle $\left({ }^{\circ}\right)$ & $110.82 \pm 6.13$ & $116.72 \pm 9.24$ & - & - \\
\hline Wetting time (min) & $10.00 \pm 0.52$ & $18.50 \pm 2.50$ & $0.07 \pm 0.02$ & $0.07 \pm 0.02$ \\
\hline
\end{tabular}
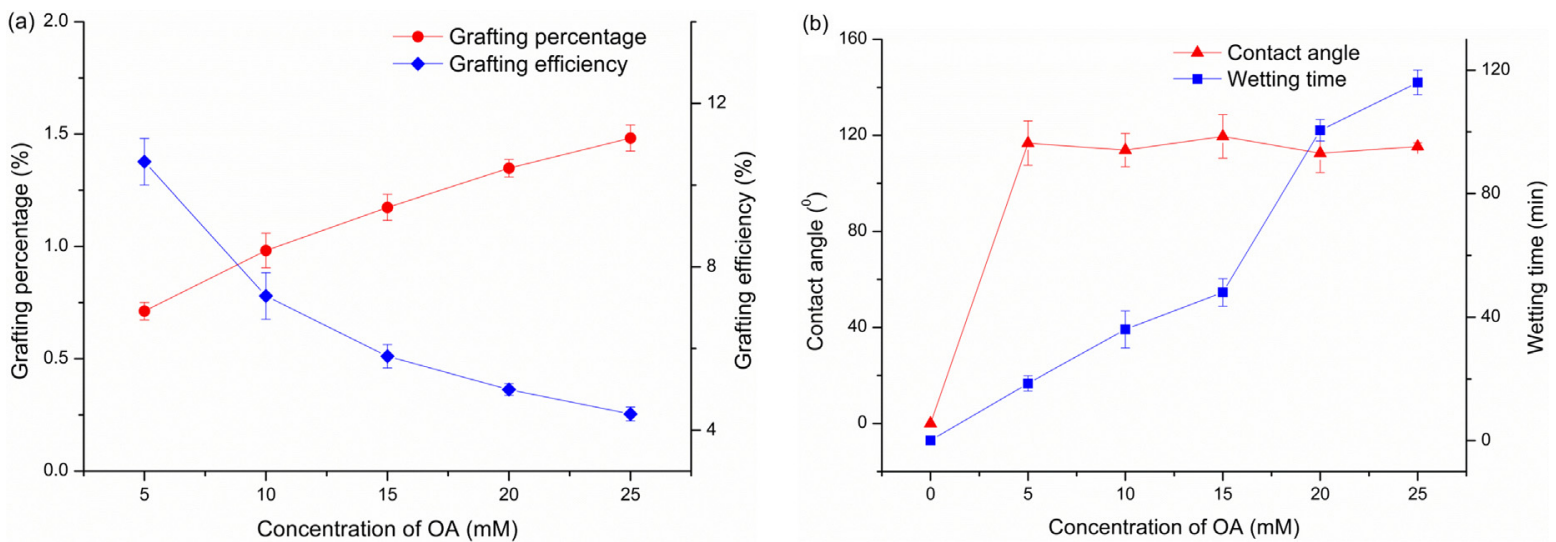

Fig. 9. The variations of the grafting percentage, grafting efficiency and the contact angle, wetting time with the increasing of OA concentration in the grafting reaction.
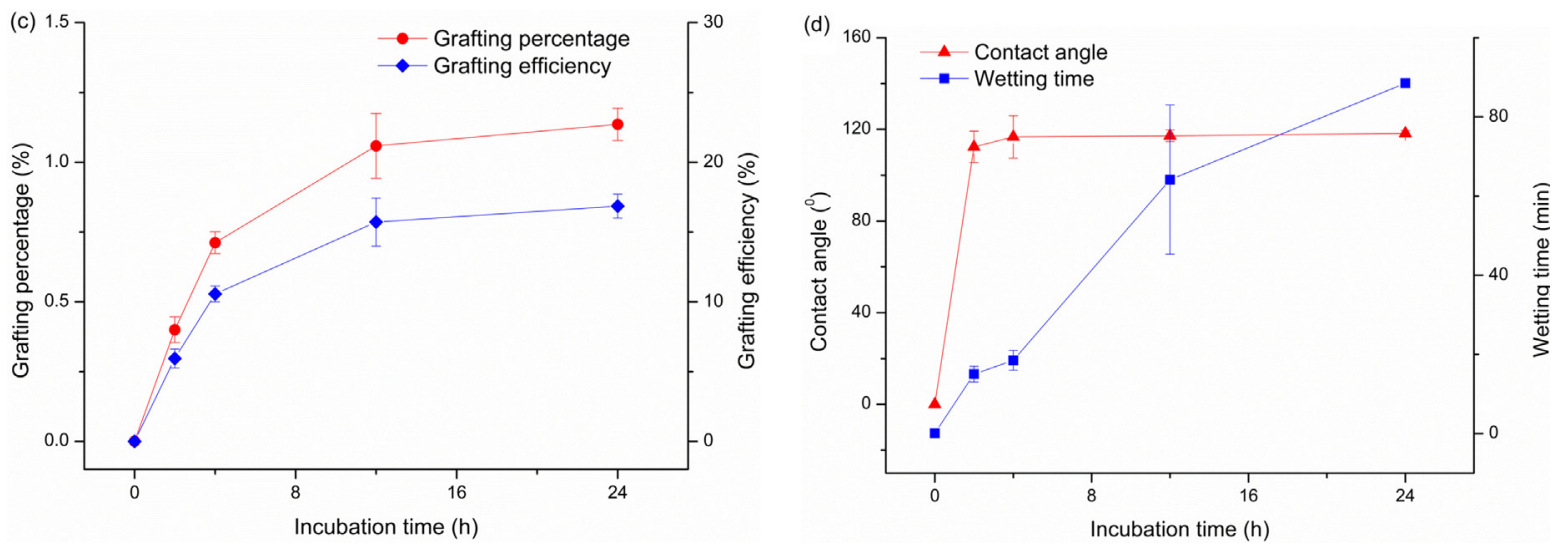

Fig. 10. The variations of the grafting percentage, grafting efficiency and the contact angle, wetting time with the increasing of incubation time in the grafting reaction.

in OA concentration, the Gp increased steadily, whereas the GE decreased gradually. The grafting degree of OA monomers in the laccase/OA treatment was directly proportional to the OA concentration, because the OA-grafting reaction on the jute surface did not involve OA-homopolymerization. In terms of jute hydrophobicity, the wetting time showed a different increasing trend than the contact angle. The wetting time of jute fabrics increased gradually with $\mathrm{OA}$ concentration. The contact angle of the jute fabrics after the laccase/OA treatment dramatically increased than the control samples, but stabilized with the increase in OA concentration. This can be explained by the fact that the jute fabric surface was uneven and contained micropores because of rough weaving, and thus a further increase in the surface hydrophobicity did not remarkably increase the surface contact angle as the other tight fabrics.

Fig. 10 shows the effects of incubation time on the grafting level and hydrophobicity of jute fabrics. The Gp and GE increased synchronously with incubation time. The grafting degree first rapidly increased when the incubation time was $<12 \mathrm{~h}$ and then stabilized with a slight increase. The surface hydrophobicity of the jute fabrics increased with increasing incubation time in the enzymatic grafting process. The increasing trends of the wetting time and contact angle were consistent with those obtained by the OA concentration.

\section{Conclusions}

This study demonstrated the covalent grafting of OA onto jute surface mediated by laccase and the increase in the surface hydrophobicity of the jute fabrics after the enzymatic grafting of hydrophobic OA molecules. The lignins isolated from the jute fabrics were analyzed by MALDI-TOF MS, ${ }^{1} \mathrm{H}$ NMR, ${ }^{13} \mathrm{C}$ NMR, and HSQC-NMR. The OA-grafted jute surface was characterized by FT-IR, XPS, and SEM. The Gp and GE values were $0.712 \%$ and $10.571 \%$, respectively. A contact angle of $116.72^{\circ}$ and a wetting time of $18.5 \mathrm{~min}$ indicated that the surface hydrophobicity of the jute fabrics increased after the graft modification, and the jute achieved excellent water repellency. The Gp and hydrophobicity increased with the OA concentration and incubation time in the enzymatic grafting reaction. The increase in OA concentration decreased the GE, whereas the increase in incubation time increased the GE. In conclusion, this eco-friendly enzymatic process provides an attractive alternative to the current methods for improving the surface hydrophobicity of jute or other lignocellulosic textile fibers.

\section{Acknowledgements}

This work was financially supported by National Natural Science Foundation of China (51173071), Program for New 
Century Excellent Talents in University (NCET-12-0883), Program for Changjiang Scholars and Innovative Research Team in University (IRT1135), Fundamental Research Funds for the Central Universities (JUSRP51312B), Graduate Student Innovation Plan of Jiangsu Province of China (CXZZ13_0752) and Doctor Candidate Foundation of Jiangnan University of China (JUDCF13023).

\section{References}

[1] L.Y. Mwaikambo, Afr. J. Sci. Technol. 7 (2006) 120-133.

[2] X. Cao, B. Ding, J. Yu, S.S. Al-Deyab, Carbohydr. Polym. 90 (2012) 1075-1080.

[3] B.C. Chattopadhyay, S. Chakravarty, Geotext. Geomembr. 27 (2009) 156-161.

[4] M.S. Jahan, S. Rawshan, BioResources 4 (2009) 921-931.

[5] A.K. Mohanty, M. Misra, Polym.-Plast. Technol. 34 (1995) 729-792.

[6] L.A. Pothen, S. Thomas, J. Appl. Polym. Sci. 91 (2004) 3856-3865.

[7] N. Sgriccia, M.C. Hawley, M. Misra, Compos., A-Appl. Sci. 39 (2008) 1632-1637.

[8] G. Mehta, L.T. Drzal, A.K. Mohanty, M. Misra, J. Appl. Polym. Sci. 99 (2006) $1055-1068$

[9] S. Kalia, B.S. Kaith, S. Sharma, B. Bhardwaj, Fiber Polym. 9 (2008) 416-422.

[10] M. Popescu, M. Totolin, C.M. Tibirna, A. Sdrobis, T. Stevanovic, C. Vasile, Int. J. Biol. Macromol. 48 (2011) 326-335.

[11] C. Mai, H. Militz, Wood Sci. Technol. 37 (2004) 453-461.

[12] N.L. Moigne, M. Longerey, J.M. Taulemesse, J.C. Bénézet, A. Bergeret, Ind. Crop. Prod. 52 (2014) 481-494

[13] S. Kalia, K. Thakur, A. Kumar, A. Celli, J. Mol. Catal. B-Enzym. 102 (2014) 48-58.

[14] A. Hüttermann, C. Mai, A. Kharazipour, Appl. Microbiol. Biotechnol. 55 (2001) 387-394.

[15] M. Nasir, A. Gupta, M.D.H. Beg, G.K. Chua, M. Asim, RSC Adv. 4 (2014) 11520-11527.

[16] G.S. Nyanhongo, T. Kudanga, E.N. Prasetyo, G.M. Guebitz, Adv. Biochem. Eng.-Biotechnol. 125 (2011) 47-68

[17] T. Kudanga, G.S. Nyanhongo, G.M. Guebitz, S. Burton, Enzyme Microb. Technol. 48 (2011) 195-208.
[18] T. Kudanga, E.N. Prasetyo, J. Sipilä, G.S. Nyanhongo, G.M. Guebitz, Process Biochem. 45 (2010) 1557-1562.

[19] S. Riva, Trends Biotechnol. 24 (2006) 219-226.

[20] M. Azadfar, A.H. Gao, S. Chen, Int. J. Biol. Macromol. 75 (2015) 58-66.

[21] M. Lahtinen, K. Kruus, P. Heinonen, J. Sipilä, J. Agric. Food. Chem. 57 (2009) 8357-8365.

[22] T. Kudanga, E.N. Prasetyo, P. Widsten, A. Kandelbauer, S. Jury, C. Heathcote, ]. Sipilä, H. Weber, G.S. Nyanhongo, G.M. Guebitz, Bioresour. Technol. 101 (2010) 2793-2799

[23] E. Aracri, A. Fillat, J.F. Colom, A. Gutiérrez, J.C. del Río, Á.T. Martínez, T. Vidal, Bioresour. Technol. 101 (2010) 8211-8216.

[24] J. Garcia-Ubasart, T. Vidal, A.L. Torres, O.J. Rojas, Biomacromolecules 14 (2013) 1637-1644

[25] T. Kudanga, E.N. Prasetyo, J. Sipilä, G.M. Guebitz, G.S. Nyanhongo, J. Biotechnol. 149 (2010) 81-87.

[26] R. Childs, W. Bardsley, Biochem. J. 145 (1975) 93-103.

[27] D.V. Evtuguin, C.P. Neto, A.M.S. Silva, P.M. Domingues, F.M.L. Amado, D. Robert, O. Faix, J. Agric. Food. Chem. 49 (2001) 4252-4261.

[28] K. Lundquist, B. Ohlsson, R. Simonson, Svensk Paperstidning 80 (1977) 143-144

[29] P. Bocchini, G.C. Galletti, R. Seraglia, P. Traldi, S. Camarero, A.T. Martinez, Rapid Commun. Mass Spectrom. 10 (1996) 1144-1147.

[30] M.S. Jahan, S.P. Mun, Bangladesh J. Sci. Ind. Res. 44 (2009) 271-280.

[31] E.N. Prasetyo, T. Kudanga, L. Qstergaard, J. Rencoret, A. Gutiérrez, J.C. del Río, J.I Santos, L. Nieto, J. Jiménez-Barbero, A.T. Martínez, J. Li, G. Gellerstedt, S. Lepifre, C. Silva, S.Y. Kim, A. Cavaco-Paulo, B.S. Klausen, B.F. Lutnaes, G.S. Nyanhongo, G.M. Guebitz, Bioresour. Technol. 101 (2010) 5054-5062.

[32] K.M.G. Hossain, M.D. González, G.R. Lozano, T. Tzanov, J. Biotechnol. 141 (2009) $58-63$

[33] P. Nzokou, D.P. Kamdem, Surf. Interface Anal. 37 (2005) 689-694.

[34] H. Zhou, D. Yang, X. Wu, X. Qiu, Chem. J. Chin. Univ. 34 (2013) 218-224.

[35] W. Wang, Z. Cai, J. Yu, Z. Xia, Fiber Polym. 10 (2009) 776-780.

[36] C. Baley, F. Busnel, Y. Grohens, O. Sire, Compos., A-Appl. Sci. 37 (2006) 1626-1637

[37] G.S. Nyanhongo, T. Kudanga, E.N. Prasetyo, G.M. Guebitz, Biotechnol. Genet. Eng. 27 (2010) 305-330. 